\title{
Theory and Practice of Competency-Based Approach in Education
}

\author{
Aimzhan Tulegenovna Makulova ${ }^{1}$, Gaukhar Mukhtashevna Alimzhanova ${ }^{1}, Z^{2}$ anar Mustafaevna Bekturganova ${ }^{1}$, \\ Zaure Asetovna Umirzakova ${ }^{2}$, Laura Tulegenovna Makulova ${ }^{3} \&$ Kulzinat Meirambaevna Karymbayeva ${ }^{3}$ \\ ${ }^{1}$ Turar Ryskulov New Economic University, Almaty, Kazakhstan \\ ${ }^{2}$ Abay Kazakh National Pedagogical University, Almaty, Kazakhstan \\ ${ }^{3}$ Taraz State Pedagogical Institute, Taraz, Kazakhstan
}

Correspondence: Aimzhan Tulegenovna Makulova, Turar Ryskulov New Economic University, Jandosova Street, 55, 050035 Almaty, Kazakhstan.

\author{
Received: February 19, 2015 Accepted: March 20, 2015 Online Published: July 28, 2015 \\ doi:10.5539/ies.v8n8p183 URL: http://dx.doi.org/10.5539/ies.v8n8p183
}

\begin{abstract}
Economic changes not only in the country, but also in the global labor market explain the increasing requirements to young specialists. There are new requirements to the model and quality of the graduate, new approaches to their competitiveness and efficiency. XXI century universities must graduate prepared specialists, who are able to adapt to the labor market and are ready for new changes, for self education, which in turn determines the meaning and function of higher education not "for life", but "during the whole life". Qualitatively new mission, the objectives and content of modern education in the new conditions is intended to be focused not just on the fundamental knowledge, but on the labor market, and on the formation of a practically oriented skills and competencies. The article discusses the conceptual content and structure of competences and competencies in different countries, the problem of professional competence is analyzed on the example of the United States, European countries, Russia and Kazakhstan.
\end{abstract}

Keywords: competence, competency, key competences, professional competence, education

\section{Introduction}

As we know, "competency based approach" has been extended at the beginning of the XXI century in connection with discussions about problems and ways of modernization of the education. Innovative education-is not only a new way of teaching, but also a new way of thinking. This education is focuses not on the transfer of knowledge, which constantly outdates, but on mastering the core competences that allow then to acquire knowledge on their own.

Competency based approach in education is well-known to the educators and scientists all over the world, and today it is discussed from different angles and is being viewed from different perspectives. First of all, this is due to the definition of the terms "competence" and "competency". According to the dictionary Webster, the term "competence" appeared in 1596. And in the United States it was firstly used in the 60s in the context of performance-based education, which purpose was to train specialists who can successfully compete in the labor market (Berkaliev et al., 2007).

The dictionary of Ozhegov adheres to activity-based description of the concepts: 1) Competence-a capacity, an area of issues, phenomena to be controlled by somebody; 2) competency-awareness; 3) competent-is a recognized expert in a particular issue (in the insurance issue), who has competence, and 4) willingness-consent to do something (risk assessment), the desire to contribute something (risk spreading). Here the word "willingness" is considered on the one hand, as a state of readiness of a person, who is able and willing to fulfill something. On the other hand, willingness-is consent to do something, a condition in which everything is done, everything is ready for something (Ozhegov \& Shvedova, 1993).

In the glossary of terms, published in 1997 by the European Training Foundation, competence is defined as "the ability to do something well or effectively, correspondence with the demands for a job: the ability to perform specific work functions." These methods reflect the following models: "competence model, based on the parameters of the individual; competence model for solving problems; model for productive activity; competence model for controlling the results of the activity" (Glossary, 1997). 
To date, competence is "a person's ability to carry out any activity on the basis of life experience and the acquired knowledge and skills".

In contrast to the competence, which is usually considered in terms of knowledge and skills acquired during the training and forming the content side of this training, competency means properties, personality traits, determining its ability to perform activities on the basis of the acquired knowledge and the develop skills and abilities (Azimov et al., 2009).

But competence is "a combination of knowledge, skills, abilities formed in the process of learning of a particular discipline, as well as the ability to perform any activity on the basis of the acquired knowledge, skills, abilities" (Azimov et al., 2009).

\section{Issues Evolution}

It entered in the theory and practice of education, because of the scientist and linguist Chomsky (1969). In his theory competence means a cognitive system of rules, by which speech rules are generated. Based on the theory of Sossyura, he outlined the ratio of "competence" and "competency", as well as the concepts of "language" and "speech" (Chomsky, 2010). According to his theory "between the competence (knowledge of his own language by a speaker or a listener) and the use - the actual use of the language," there is a difference.

Using, according to N. Chomsky, is a manifestation of competence in different activities; it is associated with human's thought and experience. That "use" and "experience" of the language's use in an "action" became the basis for the further development of this term. Today, these terms are widely used, due to the need to modernize and adapt education to the new conditions.

The first stage in the evolution of these terms, according to the Russian scientist Zimniy, is associated with the name N. Chomsky. It indicates the 1960-1970 as the first stage in the formation of terms. In this period there is a distinction between the concepts competence / competency, the development of transformational grammar and language teaching theory, the study of different kinds of language competence, the introduction of the concept of "communicative competency" (Zimnyaya, 2004).

The second stage-1970-1990 years-is characterized by the use of the category "competence"/“competency" in the theory and practice of language teaching (especially non-native), professionalism in management, leadership, in teaching communication; the concept of "social competences / competencies is developed"; the emergence of the works of Dzh. Raven "Competency in modern society", which appeared in London in 1984; studying competence in teaching, identifying the types of competence and their use in various activities.

Zimnyaya notes that the division of competence by activity types begins with this period. She cites the example of the Council of Europe, which has provided the strategic, social, sociolinguistic, linguistic and learning for language competence/competency.

Dzh. Raven defines competency as a phenomenon that consists of a large number of components. He also identifies 37 components of competency. These components are "relatively independent of each other, ... some of the components are likely from cognitive sphere, and other-from emotional ... these components can be used interchangeably as components of effective behavior" (Raven, 2002). In this case, as stressed by Dzh. Raven, "types of competencies" are the essence of "motivated abilities" (Raven, 2002), they correspond to values. In accordance with this definition in this period models of learning are developed, competences are considered as a result - as a product of the learning process.

As an example of the study of this problem in Russia I. A. Zimnyaya gives the works of N. V. Kuzmina and L. A. Petrovskaya (Kuzmina, 1990; Petrovskaya, 1989). N. V. Kuzmin considers the professional competency in the work of teachers, and determines its composition of the five elements or types of competencies.

The third stage of studying competencies as a scientific category, she connects with education, since 1990. From this period the is an intensive development and discussion of various programs of competency-based approach, a set of core competencies and specific ways of their implementation at all levels of the education system, in order to achieve the desired outcome of education.

From this period the whole world was fully absorbed by this problem. During this period, in the writings of Spencer, the question of competence is considered from the point of view of the management theory. He used a behavioral interview (Behavior Event Interview) developed by McCleland.

BEI method used to demonstrate the differences between the candidates, who have been recognized by expert opinion as having a high degree of severity of a particular quality, and those who, according to the experts, have a middle level of expression of this quality. Spencer in his book described this method and generalizes the 
experience of 286 studies conducted in different types of organizations, and on this basis he made a Dictionary of 21 competences found in people who are successful in professions of middle and high levels. The book marks out reference points for the development of competences researches.

In the first period of development of the competency-based approach in education, the researchers have focused on situations that arise in real activity. However, the current life situations are characterized by increasing complexity and dynamics. This means that people should be able to function in a complex dynamic environment. Competency-based education should help the person to solve new problems in unfamiliar situations.

The process of using skills acquired in situations in which these skills are referred to, is called long-range transport (fartransfer). For long-range transport is important to teach the students about what they may face in the future, and what can they apply in any situation. Therefore, in education there is a focus on core competences, which allow developing different skills constantly.

According to I. A. Zimnyaya, the third stage of development "is characterized by the fact that in the documents and UNESCO materials there is a group of competences, which have to be considered as a desired outcome of education" (Zimnyaya, 2004).

As an example, she gives Jacques Delors' report entitled "Education: A secret Treasure". He in this report takes the basis of "four pillars" of education: learning how to know, learning how to do, and learning how to live together, learn how to live" (Delors, 1996). All these components are a prerequisite for competency, and a prerequisite for professional competency.

Works of K. Keen are of a great interest in this period, he compares competencies with the fingers on the hand, they are - skills, knowledge, experience, contacts, values. In this form, these competencies are coordinated by the hand and controlled by the nervous system that controls the hand as a whole (Keen, 1992).

One of a large-scale researches on the issue of competences was OESR study "Identification and selection of competences: theoretical and conceptual bases» (Definition and selection of competencies: theoretical and conceptual foundations-DeSeCo) in 1999. In the study competences were not considered in terms of simple functioning of the society and the survival of individuals, but in terms of well-functioning society and a successful life of everyone in it (Selection of key competencies).

The study involved 12 countries and covered different areas of knowledge. Identification and selection of key competences and indicators of education was conducted in different countries at an international level.

Frequently mentioned competences or components were identified, such as: the ability to process information, to solve problems, to think critically, the possession of native and foreign languages, numeracy, the ability to learn throughout life, personal competences required for participation in the political or civil life, etc.

Council of the EU has also carried out work on education, youth and culture. In their studies they were offered eight components, necessary for citizens in the society, based on knowledge: the ability to communicate in their native language; the ability to communicate in foreign languages; mathematical competence and basic competences in science and technology; digital competence; the ability to learn; social and civic competence; the ability for initiative and entrepreneurship; cultural competence (Brussels, 2006). These competences are intended to achieve success in economy, based on knowledge.

Hutmacher, in turn, pays special attention to the following competences: political and social competences, competences related to the life in a multicultural society; competences related to the possession (mastery) of oral and written communication, competences associated with an increasing informatization of the society, the ability to learn throughout life as the basis of lifelong learning in the context of both personal professional and social life (Hutmacher, 1997).

\subsection{Competency Based Approach in Education in Russia and Kazakhstan}

Kazakh scientists began to discuss the issue of competency since the late 90 s. In connection with the integration of Kazakhstan education with the world trend, this question predetermined the importance of competency-based, result-oriented education.

In 2010, Kazakhstan signed the Bologna Declaration, and joined the Bologna Process. The purpose of Kazakhstan's participation in the Bologna process - improving access to European education, further enhancing of its quality, as well as increasing the mobility of students and teaching staff through the adoption of comparable levels of higher education, the use of the credits system, giving the graduates of Kazakh universities European Diploma Supplement (GOSO 2013).

Sustainable development, competitiveness of the economy and the country depends on the development of 
human's capital, which is due to the development of the educational system of each country. Kazakhstan, as well as other countries of the world strives for sustainable development and for the creation of a competitive society. In this regard, measures were taken to ensure this strategic objective.

A proof of this is the "State Program for Development of Education of the Republic of Kazakhstan for 2011-2020" adopted in 2011. Kazakhstan, adopting international experience of foreign countries, has identified education as a priority direction for sustainable development of the country. The program states that "human capital is essential for the creation of technically progressive, productive workforce that can adapt to a rapidly changing world" (Program, 2011).

Therefore, the program proposes a new national vision "by 2020 Kazakhstan-an educated country, smart economy and a highly skilled workforce. Development of education should be a platform on which the future economic prosperity of the country will be built" (Program, 2011).

When you create a unified educational space, the definition of key competencies, taking into account national situations and features of the country, is particularly important. And In 2003, together with the Soros-Kazakhstan Foundation, they discussed the issue of "Development of a national standard of general secondary education in a changing world."

Based on international experience and expert from foreign countries assistance The result was a domestic model of key competences, including 6 groups of key competencies: communicative competence; mathematical competence; scientific and technological competence; personal and interpersonal competence; cultural and civic competence; competence of work and entrepreneurship (project of MON RK and the Soros Foundation, 2003). Today the introduction of these competences in the education system, and the content of each discipline are being realized, in the frameworks of the possibilities and potential of each object (Nurgaliyeva et al., 2007; Tazhigulova, 2009).

Russian scientist Khutorskoi (2002) also identified the following types of competences, taking into account his national characteristics of education: value and meaningful, common cultural, educational and informative, informational, communicative, social and labor, personal competences.

Khutorskoi (2002) considered the definition of competence in terms of the importance of education, calling them "educational competences." According to his definition "educational competence-is a set of semantic orientations, knowledge, skills and experience of the student's activity, in relation to a certain range of objects of the reality, necessary for the implementation of personally and socially meaningful productive activity».

The proposed competences of different countries are designed to provide a link between practice and education, to provide the necessary knowledge, skills and relationships, which will help people to navigate in the rapidly changing world. Therefore, the key competences are defined as multifunctional package of knowledge, skills and relationships that are necessary for each person for a full-fledged personal life and work, active civic stand and effective social inclusion (Recommendations, 2006).

The volume of competencies, as well as their non demarcation makes it difficult to plan, and to implement them in the learning process. Therefore, scientists also classify competencies according to their hierarchy. A. V. Khutorskoi divides them into: key competences-related to common (met subject) educational content; general-subject competences-related to a particular range of educational subjects and educational areas;-subject competences-private in relation to the two previous levels of competences, with a specific description and the ability to be formed in educational subjects (Recommendations, 2006).

There is also a classification of I. A. Zimnyaya, which differentiates three main groups of competencies: competencies related to himself as an individual, as a subject of life; competencies related to the interaction with other people; competencies related to human's activity, manifested in all its types and forms.

Scientists attempted, firstly, to identify and theoretically justify the basic groups of key competencies, secondly, to define some of its basic necessary nomenclature, and thirdly, to determine the components of each of these or the types of competencies.

\subsection{Professional Competence and the Methodology of Its Study}

To date, specific types of competences associated with each level of education are identified. Professional development of the person is inseparable from his person personal development. Professional competence, along with professional orientation and professional flexibility is the main object of professional development and a form of the implementation of human's creativity in professional work. Professional competency means theoretical and practical readiness for professional activities. 
Psychological patterns of professional growth, specifics of the development of professional competency in the process of professional self-determination in the current socio-economic conditions were almost completely studied by E. F. Zeer.

Professional competence he considers as one of the main substructures of the subject of professional work, along with the thrust of the individual, professional qualities, professionally important psycho physiological properties. Therefore, modern universities around the world are trying to determine the professional competence, the model of the graduate, who meets all the requirements of the market and who is ready to navigate in a rapidly changing world.

Professional competence of the graduate can be viewed from different perspectives. There are functional, behavioral, multi-dimensional and holistic approaches to study this question.

Behavioral approach considers professional competence in terms of the importance of the behavioral competence, which is defined as a relatively stable personality characteristics causally related to an effective or superior job performance. It is believed that White (1959) introduced the term "competence" to describe the personality characteristics that are most closely related to the "perfect" job performance and high motivation. Competency-based approach began with the observation of the successful and effective performers, in order to determine what these people are different from less successful ones.

Competence thus captures skills and properties located outside of cognitive abilities, such as self-awareness, self-regulation and social skills; while some of them may also be incorporated into individual taxonomy. Competences, which are largely behavioral characteristics, as opposed to personality and intelligence, can be formed through the training and development (Francoise \& Winterton, 1998). This tradition is particularly strong in the US, where competences are defined in terms "the basic characteristics of people" which are "causally related to effective or" excellent job performance "and" manifest themselves in a variety of situations for a long period of time (Boyatzis, 1982; Spencer, 1993). Hay Group (1996) demonstrated the breadth of using this approach in USA companies.

The functional approach focuses on functional competences and on the ability to demonstrate a work that corresponds to the standards, necessary for effective performance, "the ability to perform actions in the workplace under the standards used for the professions." The definition also included "skill and understanding" and "aspects of personal effectiveness" (Francoise \& Winterton, 1998).

In this approach, it becomes important to develop a competence model for particular professions, for example we give the UK, where a variety of competences models were used for the formation of payment and management systems on the basis of competences.

In the multidimensional and holistic approach substantive competences personal competence and social competences are taken into account. This approach is reflected in the system of Germany, France, and Austria. In 1996, the German education system has adopted the approach of "action competences", moving from subject to competences and curricula, which largely determines the fields of study, and to a lesser extent is related to work: knowledge and skills.

Competences related to the activity area, describes the willingness and ability, on the basis of subject knowledge and skills, to perform tasks, solve problems and evaluate the results consistently and independently in accordance with the objectives.

General cognitive competences, the ability to think and act in a perspicacious and problem-solving method, are a prerequisite to develop the subject competences, which, in turn, include both cognitive and functional competences.

Personal competences describe the willingness and ability to understand, analyze and evaluate possible ways of development, requirements and restrictions in the personal, work and social life, to develop their own skills as successfully as they select and implement their life plans. Personal competence includes such individual properties as "independence", "critical abilities", "self confidence", "reliability", "responsibility" and "sense of duty", along with professional and ethical values. Personal competences thus include cognitive and social competences.

In some cases, self-competence is defined as the ability to act morally and independently, which includes upholding a positive self-image and the development of morality.

Social competences describes the willingness and ability to create and maintain relationships, identify and understand the potential benefits and threats in relationships, as well as the ability to interact with others in a 
rational and fair manner, which includes the development of the sense of social responsibility and solidarity. Social competence thus includes functional and social competences.

The balance of subject, personal and social competences-is a prerequisite for "meta competence and competence for learning. Meta competence-is an extension of cognitive and subject competences, which are the result of transversal strategies and processes of the invention and problem solving, while, the teaching competence equates to the meta-competences: «learning how to learn».

To define the competency requirements for graduates it is necessary to come up with a holistic approach, as their competence is measured by how much they can cope with professional responsibilities and how "better" to carry out their professional activities.

A holistic approach to competency, joining knowledge, understanding, values and skills that are "inherent in people, who are professionals", is appropriate in terms of their practical orientation.

Summing up the experience of scientists, the model of professional competence can be defined as follows:

- Cognitive competences, which include not only formal knowledge, but also informal-based on experience. Knowledge (know-what), supported by the understanding (know-why) differ from competences.

- Functional competence (skills), include that "a person who works in this professional area, should be able to do ... is able to demonstrate."

- Personal competences (behavioral competences, "know how to behave"), defined as "relatively stable personality characteristics, causally related to an effective or superior job performance."

- $\quad$ Ethical competence, "personal opinion and professional values, the ability to make decisions based on them in work situations."

- Meta-competences refer to the ability to cope with uncertainty, as well as with the teachings and criticism.

In contrast to the Russian and Kazakh scientists, foreign researchers focused on the practical orientation of this issue.

Here there are two important principles of research: fundamentality and practical orientation of education.

The first one provides a systematic assimilation of knowledge, the other-its practice-oriented integration. In the first case we take into account the theoretical basis of the issue, and we consider the systemic and systematic implementation of competency-based approach. The fundamental solution of the problem involves a vertical resolution of this issue, and mainly comes from the top. In the second case the solution of the problem comes from the bottom, and is a horizontal system of problems. In this aspect, competency-based approach is deeply studied by PR management of foreign countries.

\section{The Practice of Introducing Competency-Based Education}

The competency of graduates has become the object of study of many foreign, Russian and Kazakh scientists. Since the competency of graduates is a generic result of the whole education process, the main aim in the implementation of GOSO, an integrating principle of the graduate "model".

Competence model of the graduate must guarantee getting a qualification corresponding to his future career. It is expected that competences acquired by the student in high school, will manifest themselves in different domestic and professional situations.

In this case, there are two groups of competencies: versatile (universal, over objective) and specific (objective-specific, objective-specialized).

Flexibility to move from versatile competences into new types of activities, which manifests itself in the ability to use the existing knowledge and experience in new conditions and less rigid attachment to the objects and labor tools, is one of their main characteristics.

Special competences reflect the professional qualification. They differ for different disciplines (directions, special training). Despite the existence of two types of competences, the description of both versatile and specific competences is possible only with a sufficiently high degree of generalization and "transpersonal" nature of their content.

Despite this, the Russian scientists adhere to their traditional features of the education system, and according to them, a special condition for the implementation of GOSO is "concretized learning outcomes, which are definable and measurable", also take into account the «the development of spiritual values of the students, the establishment of their civic and patriotic consciousness» as a distinctive feature of the national education 
system.

In this regard, they offer to be guided by key, general cultural, social (Zimnyaya, 2004) competences. Because they believe that through these competences a person's ability is realized not only to adapt to the constantly changing reality, but also to change this future in accordance with his understanding, professional plans to provide a more comfortable and effective self-realization.

The difference between these competences and special/professional ones is that they not only reflect the ability of the person to use the acquired knowledge, the available skills, the known methods of activity, but also demonstrate its ability to create new meanings, information, objects of reality in the process of continuous self-improvement .

This issue has become particularly relevant with the adoption of a new generation of GOSO, which was vigorously debated among Russian scientists. According to them, in the new generation of GOSO, while determining the conditions for the formation of versatile competences, we did not take into account the capabilities of the system of education, and the following recommendations were not in demanded, "...we should not expect that only through education content we can achieve mastery of competences. The fact is that the formation of certain competences cannot be on the "charge" of only individual disciplines, or even the content of the entire educational program. Competences-are also the result of educational technologies, methods, organizational forms, learning environment, etc. (Zimnyaya, 2004).

Some problems of competency-based approach in determining the content of education exist in Kazakhstan's higher education system. To date, basic or core competences for all levels of the education systems were defined. The question of the competency-based approach is solved at the level of state educational standards of education. We determined the limits of the competencies of preschool education, secondary education, technical and vocational education, post-secondary education, higher and postgraduate education.

In the higher education system of Kazakhstan, "competence" is defined and used as "the students' ability of the practical application of the acquired during the learning process knowledge, and skills in their professional activities." And learning outcomes are determined on the basis of Dublin descriptors, and assume the following abilities: 1) demonstrate knowledge and understanding in the studied area, including elements of the most advanced knowledge in this area; 2) to apply this knowledge and understanding in a professional manner; 3 ) formulate arguments and solve problems in the studied area; 4) to collect and interpret information to make judgments taking into account social, ethical and scientific considerations; 5) give information, ideas, problems and solutions, to both specialists and non-specialists.

In the context of Kazakhstan's higher education, these descriptors are expressed in the following competences: 1) general competences: social and ethical competence; economic, organizational and managerial competences; willingness to change the social, economic, professional roles, geographical and social mobility in terms of the increasing dynamism of changes and uncertainties; 2) Special competences. The last kind of competences is developed for each specialty of higher education on the basis of professional standards taking into account the requirements of employers and social demands of the society. Indicators of these competences are described in standards and curricula of each university.

But the real level of its formation can be judged only when the graduate will start an independent professional activity. In the process of training in high school we can only assess competences. In pedagogical science, the perception of competences has already settled as the basic components of the potential competency that can be demonstrated by the university graduate in the future. According to this, A. V. Khutorskoi offers the following definition of competence, a "kind of estranged, preassigned requirement for student's educational attainment," and the term "competency" to be used to capture the already establish personality traits, "the person's ownership, possession of an appropriate competence, including his personal attitude to it, and to the subject of activity" (Khutorskoi, 2002).

\section{The Results of the Measurement of Professional Competence}

Evaluation of student's mastery of competence is usually given by other entities (e.g., teachers, whose criteria can be subjective, or employers, whose own competence may be questionable). Therefore, one of the tasks which can provide a real boost to the quality of education is an adjustment of the main players, involved to identify competences.

Opinion of four groups of respondents, who are interested in determining the competency of the graduates: 1) employers; 2) representatives of the academic community; 3) professionals (their associations, unions); 4) graduates-greatly varies in determining its content and the significance of individual types of competences. 
Especially in the formation of competences we should not forget about the potential customer-the employer. Different activities require different competences of the employee. Not all competences are equally useful in a particular activity.

Therefore, the educational institution must apply to the customer, who will build a professiogram-a list of competences of a specialist-a graduate. List of competences may change over time. Professiogram-is a form of profession which is in demand in the market, and necessary for the employer.

Competency is a quality that manifests itself only when a person goes to work, for it is a sign of professionalism of the employee. Competence of the person is potential and relative at the same time (Tatur, 2004). Competency-based model of a specialist is not a model of a graduate, because competency is inextricably linked with the experience of a successful activity, which the student can acquire in the proper amount during the course of training in the university.

Therefore, in the development of the competency-based model of the graduate, as the goal of higher education we should reduce the competency-based model of the specialist, beforehand reducing the requirements that are related to professional experience.

On the other hand, it is necessary in the educational program to increase all learning activities (various educational practices, project works, teaching and research work of students, business, role-playing, simulation games, etc.) (Tatur, 2004)

Competency-based approach, as we can say - is an association of the interests of the employer's, the graduate, the teachers and professionals in order to realize the professional activities in the best way. Therefore, in order to assess the current existing requirements of professional competence in high school, we should be guided by the views of employers.

Since the competency-based approach is to bring together education and work, we tried on the basis of the economic university to find points of coincidence of these four circles of respondents. In the study, we analyzed: GOSO, typical programs, curricula, textbooks and teaching aids, educational complexes of disciplines (ECD). The purpose of the analysis was - to assess the content of education and to determine the function of the discipline in the formation of the professional competence of students. Of course, a huge role is played by special items, selected in the formation of specific competences. The formation of certain competences is done through different disciplines, which are determined in the curricula and teaching complexes of each subject.

Interviews were conducted with employers, on the following questions "What professional skills of young professionals you encourage? What professional skills would like to see in young specialists, necessary in your work?" Almost all employers indicated a lack of practical skills of professional activity in young specialists.

We also conducted a survey of university graduates, who had just started his career. To determine the level of "readiness" and "formation" of professional competency, we made a questionnaire for graduates on the following issues:

- What brings you joy in your work? Are you satisfied with your job?

- What do you think, what qualities should the system of higher education generate in students for successful job?

- What professional activities are encouraged in your work?

- What bugs did you find in yourself when you got this job?

- Knowledge of what subjects especially helped you in your professional activity?

Analysis was performed by the method of classification of judgments of the questionnaires.

The survey involved 560 graduates, it turned out that only $30 \%$ of them are satisfied with their work, as they work in their profession, or they just like their work.

In the second question, respondents noted communication, teamwork and mobility as professionally significant qualities that should be paid attention in the higher education system.

In the third question, respondents noted that it is important for the employers to have such qualities as initiative, efficiency, as well as knowledge of three languages-Kazakh as the state, Russian, English and the ability to work with clients. Accordingly, graduates in this regard were not quite ready, and this determines the importance of communicational, intercultural communication and interpersonal communication.

Many of them have noted some of the social problems, common among new specialists-it is psychological not 
readiness to accept criticism or the disease of "Excellent" student.

On the fifth question, respondents noted the importance of professionally oriented disciplines, in the formation of subject, special competences.

In the longer term the following is assumed:

1) Analysis and in-depth study of the fundamental, practice-oriented principles for each level of the education system, taking into account the principle of consistency.

2) Development of scientific methods and experimental study of professional competence as the goal and the result of higher education and the criteria for its evaluation, based on a holistic and multidimensional approach.

3) On the basis of it, to identify and correct not only the basic competence, but also special subject specific competences in specific disciplines.

4) Provide competence education that is relevant to educational and methodical complex at module-credit system. It is important to determine whether the content of education, its function in the formation of competence, efficiency, types, methods, forms and means of educational activities.

5) To determine functions of competencies as a tool for quality management education.

\section{Conclusion}

In conclusion, it should be noted that competent approach in education is being developed in different countries, in different ways. There are many problems that require special methodology and research methods. In this regard, it is useful to use and integrate the experience of other countries, and to be guided by their national characteristics of the educational system.

- In forming of education in the context of competency-based approach, we should ensure integral fundamentality and practical orientation of the study.

- Research methodology of competency-based education is based on behavioral and functional approaches, and in the study of competency, the integrity and multi-dimensional approaches are effective.

- In the study of competency we should take into account the competency of the graduates, in order to predict the potential competences as a condition of a successful career.

- In studying of competency, the unity of participants-employers, representatives of the academic community, professionals, graduates is right, to define, organize and form the necessary competences in high schools in the future specialists.

All this will help to correctly build up, adjust, and supplement competencies, to determine the composition and structure of professional competency of the future specialists, and to assess if they are well formed, because the composition of required competencies in market may change, if we take into account the conditionality of competency with the requirements of the labor market.

In the longer term it is expected to develop research methods for procedural competency as a goal and a result of education, and criteria for its evaluation, based on a holistic and multidimensional approach; integrative fundamental, practice-oriented principles, corresponding to each level of the higher education system.

It will identify and correct not only the basic competences, but also special subject competences in specific disciplines, and correctly build up the learning process.

Only after that it is important to determine whether the content of education, its function in the formation of competences, the efficiency of its types, methods, forms and means correspond to the training activities. It is also possible to determine the function of competences as a tool for education quality management.

\section{References}

Asimov, E. G., \& Shchukin, A. N. (2009). New dictionary of metodological terms and concepts (the theory and practice of language teaching). Moscow: Publishing House: ICAR.

Berkaliev, T. N., Zair-Bek, E. S., \& Tryapitsyna, A. P. (2007). Innovation and quality of school education. St. Petersburg, Publishing: Caro.

Boyatzis, R. E. (1982). The competent manager: A model for effective performance. John Wiley \& Sons.

Chomsky, N. (1969). Aspects of the syntax theory. Frankfurt. http://dx.doi.org/10.1007/978-3-322-84061-5_6

Chomsky, N. (2010). About nature and language: From the essay "The secular priesthood and the dangers posed by democracy" (second publishing). Moscow: KomKniga. 
Hutmacher, W. (1996). Key competencies for Europe. Report of the Symposium Berne, Switzerland. Council for Cultural Co-operation (CDCC). Secondary Education for Europe, Strasburg.

Keen, K. (1992). Competence: What is it and how can it be developed? Instructional Design: Implementation Issues (111-122). Brussels: IBM Education Center.

Khutorskoy, A. V. (2002). General subject content of educational standards. The project "standard of general education." Moscow.

Khutorskoy, A. V. (2002). Key competences and educational standards. Report of the Department of Philosophy of Education and the theory of pedagogy RAO. «Eidos» centre. Retrieved from http://www/eidos.ru/news/compet/htm

Kuzmina, N. V. (1990). Professionalism of teacher's personality and industrial teaching master. Moscow.

Le Deist, F. D., \& Winterton, J. (1998). Human Resource Development International, 8.

Nurgaliyeva, G. K., Tazhigulova, A. I., \& Artykbaeva, E. V. (2007). The introduction of information and communication technologies in the system of general secondary education of the Republic of Kazakhstan. Almaty: RCIO.

Ozhegov, S. I., \& Shvedova, N. Y. (1993). Dictionary of Russian language. Moscow: Az.

Petrovskaya, L. A. (1989). Competency in communication. Moscow.

Raven, J. (2002). Competency in modern society. Moscow: Kogito-Centre. Retrieved from http://www.koob.ru/raven/competence_mood_society

Spenser, L. M., \& Spenser, S. M. (1993). Competence at work: models for superior performance. New York: John Wiley \& Sons.

Tatur Y. G. (2004). Competency in the structure of the quality model of specialist' training. The journal "Higher education today", 3.

Tazhigulova, A. I. (2009). Pedagogical methodology and technology of informatization of secondary education. Almaty: NCI.

Zimnyaya, I. A. (2004). Key competencies as effectively-targeted base of competency-based approach in education. Author's version. Moscow: Research Center of the problems of the quality of specialist's training.

\section{Copyrights}

Copyright for this article is retained by the author(s), with first publication rights granted to the journal.

This is an open-access article distributed under the terms and conditions of the Creative Commons Attribution license (http://creativecommons.org/licenses/by/3.0/). 